\title{
Robert Jackson, Rethinking Religious Education and Plurality. Issues in Diversity and Pedagogy
}

London-New York, Routledge Farmer, 2004, 221 p.

Bérengère Massignon

\section{OpenEdition}

\section{Journals}

Édition électronique

URL : http://journals.openedition.org/assr/10893

DOI : $10.4000 /$ assr. 10893

ISSN : $1777-5825$

Éditeur

Éditions de l'EHESS

Édition imprimée

Date de publication : 1 décembre 2007

Pagination : 157-310

ISBN : 978-2-7132-2145-3

ISSN : 0335-5985

\section{Référence électronique}

Bérengère Massignon, «Robert Jackson, Rethinking Religious Education and Plurality. Issues in Diversity and Pedagogy ", Archives de sciences sociales des religions [En ligne], 140 | octobre - décembre 2007 document 140-42, mis en ligne le 02 juillet 2008, consulté le 21 septembre 2020. URL : http:// journals.openedition.org/assr/10893; DOI : https://doi.org/10.4000/assr.10893

Ce document a été généré automatiquement le 21 septembre 2020

(C) Archives de sciences sociales des religions 


\section{Robert Jackson, Rethinking Religious Education and Plurality. Issues in Diversity and Pedagogy}

London-New York, Routledge Farmer, 2004, 221 p.

\section{Bérengère Massignon}

L'auteur propose un panorama des différentes pédagogies en matière d'enseignement du fait religieux ou de la culture religieuse ainsi que des débats politiques qui les soustendent en Grande-Bretagne. Face au défi de la pluralité religieuse, chaque pays européen s'interroge sur la manière d'ouvrir l'enseignement religieux, souvent confessionnel et séparé, voire monoconfessionnel, à une diversité de religions, notamment à l'islam. L'enjeu est aussi de former, ensemble, les élèves afin de permettre une cohabitation pacifique : l'enseignement de la religion fait alors partie d'un projet plus large que défend Robert Jackson : l'enseignement interculturel et civique. Ce livre intéressera toute personne confrontée à l'enseignement du fait religieux en France en l'ouvrant à des débats pédagogiques d'outre-manche alors qu'en France, cet enseignement a fait l'objet de peu d'études de didactique. En raison de l'engagement et de l'influence de l'auteur comme conseiller et expert dans différents forums internationaux (Union européenne, Conseil de l'Europe, OSCE), ce livre éclairera les décideurs et le citoyen sur les tendances dominantes, en Europe, quant à la réforme des contenus et des méthodes de l'enseignement à propos de la religion. 